\title{
Educação pública: currículo e formação de jovens alunas no Ensino Médio ${ }^{1}$
}

\author{
Leny Cristina Soares Souza Azevedo* \\ Ligia Karam Corrêa de Magalhães**
}

\begin{abstract}
Resumo
Este artigo investiga a configuração do currículo no curso de formação de professores em nível médio, em uma escola pública estadual. Os dados foram coletados em 2010, 2011 e 2012, por meio de questionários e entrevistas, com 52 jovens. A partir dos depoimentos, foi possível identificar as expectativas em relação à ampliação dos estudos, a introdução no mundo do trabalho, a cultura escolar vivenciada e as lacunas e impasses desse processo de formação. $O$ texto dialoga com o contexto do ensino médio modalidade normal, com as políticas de formação docente, situando a realidade específica da instituição. Evidencia o divórcio entre a formação oferecida ao futuro professor da Educação Básica e as necessidades de profissionalização da carreira docente, em que seja conferido aos egressos o propalado protagonismo no exercício da profissão, onde os trabalhos sejam pensados em contextos sócio/político/econômico/cultural em que acontecem.

Palavras-chave: currículo; ensino médio; formação de professores, trabalho docente.
\end{abstract}

\section{Public Education: curriculum and female students education in the high school}

\begin{abstract}
This article discusses research conducted with female students in the city of Rio de Janeiro about the way the mid-level curriculum has been setting a public school in a training course for teachers. The data were collected in 2010, 2011 and 2012, through questionnaires and interviews with 52 young people. From the interviews, it was possible to identify and engage with the expectations for expansion studies, introducing at work, school culture experienced and gaps and bottlenecks in this process. The text speaks to the high school level normal mode, with training policies, locating the specific reality of the institution, highlighting the divorce between the needs of the school and the professionalization of youth and an educational system that does not offer the possibilities that enable the young, of fully, to cope with life's concrete work in public schools.
\end{abstract}

Keywords: curriculum, high school, teacher training, teaching work.

\section{Introdução}

Este texto tem como objeto de estudo a formação de professores no Ensino Médio Normal no Rio de Janeiro. Acreditamos que a discussão acerca do trabalho seja uma das grandes preocupações no campo das políticas públicas para a juventude, mostrando a necessidade de que haja projetos e ações concretas, no presente, tendo em vista a diminuição da exclusão desse grupo social e da limitada oferta de oportunidades no mundo do trabalho.

Assim, a proposta de formar professores no Ensino Médio (EM), Modalidade Normal, configura-se questão polêmica. A Resolução do CNE/CEB n.1, de 20/08/2003, que, de acordo com Brzezinski (2008), dispõe sobre os direitos dos profissionais da educação com formação de nível médio, é instrumento que reafirma e complementa o prescrito no art. 62 da LDB, que admite "como formação mínima para o exercício do magistério na educação infantil e nas quatro séries iniciais do ensino fundamental, a oferecida em nível médio, na Modalidade Normal".
A autora discute que, sob a ótica do direito pessoal e intransferível, a resolução representa avanço, considerando que resguarda, por toda a vida, o direito do professor de ser formado em curso profissionalizante do EM. Sob a perspectiva do movimento que defende a formação em nível superior do professor nas séries iniciais do ensino, isso representa um retrocesso. Esse nível de formação serve como obstáculo à busca, pelos jovens, do curso de Pedagogia. Diante dessas análises, interessa-nos aprofundar as aspirações da juventude que escolhe esse curso profissionalizante para apreendermos o sentido dessa profissionalização. Para isso, faz-se necessário recorrer aos elementos que determinam as políticas de formação, entre estas as condições históricas de sua produção, as correlações de força em presença e as perspectivas teóricas partilhadas.

Moraes e Alavarse (2011) analisam a importância do EM como uma "etapa da educação básica que, de acordo com a Emenda Constitucional (2009), tem sido objeto de um amplo conjunto de trabalhos que revelam, [...] toda a complexidade social, política e pedagógica" (p.808).

\footnotetext{
*Endereço eletrônico: leny.az@ hotmail.com.

**Endereço eletrônico: ligiakaram@gmail.com.
} 
Para empreender a discussão dessa modalidade de ensino, analisamos os depoimentos recolhidos em 2010, 2011 e 2012, em uma pesquisa realizada numa instituição pública estadual, envolvendo cinquenta e duas entrevistadas. A discussão norteou as escolhas feitas por um curso profissionalizante, as políticas para o Ensino Médio, a cultura escolar vivenciada através da organização curricular e as expectativas e perspectivas das jovens alunas para se desenvolverem no mundo do trabalho e dos estudos. Destacam-se estudos realizados sobre "ser jovem", a legislação, a cultura escolar e a formação das alunas na escola.

Ressaltamos, assim, que a opção de realizar esse estudo com alunas concluintes do Ensino Médio Modalidade Normal, nesta instituição de ensino do Rio de Janeiro, situada na região central, justifica-se por alguns motivos. O primeiro pelo fato de esse momento se configurar historicamente como profícuo para as discussões acerca da retomada, no Estado do Rio de Janeiro, do ensino médio para a formação de professores, trazendo suas "velhas" limitações e perspectivas. Outro motivo diz respeito às razões que levam jovens alunas a optarem por realizar um curso de profissionalização docente, pois é pertinente conhecer algumas das expectativas e projetos que direcionam essas jovens para o curso de formação docente, e não o de EM regular.

Quanto à opção por jovens alunas do terceiro ano do curso, explica-se como tentativa de verificar as aspirações mais latejantes no que tange à inserção no mundo do trabalho. Também nos parece relevante trazer as observações, as entrevistas e discussões feitas pelas alunas do EM, no qual se registrou o contexto educacional da instituição e a busca de compreensão do complexo universo da cultura escolar, que abrange a formação dos futuros profissionais da educação articulada às analises sobre a necessidade de construir alternativas pedagógicas para os primeiros anos da Educação Básica, tendo em vista a continuidade e as mudanças na carreira docente.

Diante dessas ponderações, desenvolvemos a análise dessa temática, apontando para elementos constitutivos do cenário sociopolítico e econômico no qual se desenvolve a educação para jovens das camadas mais pobres da população. Com esse entendimento, organizamos o texto em partes que se integram e dão organicidade à reflexão, enfocando alguns movimentos: (1) a retomada das discussões, a respeito de "ser jovem" reportando-se, aos estudos no atual processo de debates sobre a necessidade de procurar conhecer as realidades, práticas, questões políticas sobre jovens que frequentam a escola de EM; (2) o questionamento das políticas para a formação dos professores, focando a cultura escolar e a organização curricular para o ensino médio na modalidade normal; e, (3) as considerações finais: aproximações e distanciamentos entre as contribuições oferecidas pela instituição investigada e as expectativas das jovens. Impõe-se, assim, a necessidade de políticas educacionais consoantes com os princípios democráticos constituintes das práticas sociais emancipatórias e que ofereçam formação docente de forma a potencializar a influência da escola nas trajetórias sociais de pessoas jovens.

\section{Jovens Alunas: escola, continuidade dos estudos e trabalho}

Que significa ser jovem no Brasil, hoje? Quem são os jovens brasileiros? Quais são seus modos de vida, gostos, projetos, sonhos? Que esperam do futuro?

Falar e escrever sobre os jovens na atualidade é tarefa desafiante. Em primeiro lugar, porque estamos diante de uma população composta por aproximadamente 54 milhões de brasileiros $^{2}$. Em segunda instância, caminhando para além do contingente populacional, deparamonos com uma enorme diversidade existente em torno da juventude brasileira, diversidade que se concretiza nas condições sociais e econômicas, nas diferenças geográficas, de gênero, culturais, religiosas, dentre inúmeras outras.

Para dar conta dessas discussões, esse texto procura analisar as representações sociais de jovens alunas que estudam numa escola pública estadual, discutindo as trajetórias sociais e escolares associadas à escolha de um curso profissionalizante e as perspectivas de introdução no mundo do trabalho, explorando os sentidos atribuídos a educação, ao trabalho e a formação

As múltiplas transformações existentes nos cenários econômico, político e social a partir da década de 1970, intensificando-se nos anos de 1980 e 1990 até os dias atuais, vêm eclodir de forma incisiva. Tais processos provocam inúmeras mudanças no mundo do trabalho e repercutem diretamente no âmbito educacional, especificamente no Ensino Médio, visto que é nessa etapa que diversos segmentos juvenis concluem a chamada Educação Básica. A educação, assim, volta-se às demandas do mundo do trabalho, com a árdua tarefa de propiciar a aproximação dos seus sistemas de ensino às necessidades do mundo produtivo.

No que concerne as jovens do sexo feminino, observamos a preocupação das mães 
com a escolarização de suas filhas, o que se traduz na mobilização para efetivar a matrícula numa escola que tenha boa visibilidade, qualidade do ensino ministrado e a segurança de seu público. De acordo com as jovens entrevistadas essas são as razões principais dos familiares que justificam a opção pela "escola boa" como uma estratégia de investimento futuro, na busca da "empregabilidade".

Para Moscovici (2009), pessoas e grupos criam representações no decurso da comunicação e da cooperação. Representações não são criadas por um indivíduo isoladamente. Uma vez criadas, elas "adquirem vida própria, circulam, se encontram, se atraem e se repelem e dão oportunidade ao nascimento de novas representações, enquanto velhas representações morrem" (p. 41). É nesse movimento que é possível estudar as representações, suas propriedades, suas origens e seu impacto.

A proposta epistemológica que aqui se constrói entende a realidade como constructo social, e a temática do trabalho docente se constitui como objeto de diálogo entre pesquisadoras e jovens que escolheram a escola normal para completarem sua formação no Ensino Médio.

A partir dessas considerações, surgem alguns questionamentos:

- Como se delineou a trajetória e as vivências de jovens alunas no espaço escolar?

- Qual têm sido a influência e a contribuição da instituição escolar para as jovens alunas em relação à entrada no mundo do trabalho?

Acredita-se que a discussão acerca do trabalho seja uma das grandes preocupações no campo das políticas públicas para a juventude, mostrando a necessidade de que haja projetos e ações concretas no presente, tendo em vista a diminuição da exclusão desse grupo social e da limitada oferta de oportunidades no mundo do trabalho.

Os estudos realizados sobre a formação do professor, de acordo com Gatti e Barreto (2009), sugerem que,

[...] de um lado, a representação do magistério como vocação, quando evocada como substituta dos saberes especializados que informam a profissionalidade docente, tende a minimizar a importância do avanço dos conhecimentos e da pesquisa sobre os saberes dos professores e sobre os próprios conhecimentos das áreas de referência do currículo da educação básica. De outro, a persistência da representação do trabalho docente como vocação pode ser um indicativo de recontextualização dos atributos que acompanham o conceito, como a afetividade, a intuição e a criatividade do ato educativo (p.291).

Compreende-se, assim, a importância de discutirmos as representações que ainda permanecem subjacentes aos modelos de formação com forte herança histórica: por exemplo, as representações como "professora primária" e como "professora polivalente". Certamente, formar significa articular identidade pessoal e profissional, e é pertinente procurar compreender os significados dos projetos de vida dos jovens alunos em relação às representações que vão sendo construídas a respeito de ser jovem, ser estudante e o lugar do trabalho na sua vida pessoal e profissional.

As pesquisas realizadas nos anos de 2010 a 2012 registram a criação e recriação das representações que seguem desempenhando um papel de reprodução social e cultural, o que pode ser observado em dias de comemorações escolares em que os alunos se vestem de saia azul marinho com pregas, meias brancas, camisa branca e sapato preto. Ao observar essas jovens vestidas com uniforme, rememoramos as normalistas, que marcaram com suas vestimentas o inicio do século $\mathrm{XX}$. Muitas dessas jovens eram provenientes das classes médias e buscavam a formação de "professoras primárias", que foi objeto de sonhos e de orgulho nas capitais importantes do país. Assim, no imaginário da época foi-se construindo a protagonização da escola como lugar digno da instauração de uma nova ordem para efetuar o Progresso - educar as crianças brasileiras.

Visualizamos a complexidade que envolve as relações políticas, materiais e educacionais no passado e que deixou vestígios nas propostas, discursos, interesses, sonhos e sociabilidades na concretização da formação docente. Com toda a carga histórica, que motivos desencadearam a escolha pela escola de magistério na atualidade?

As jovens entrevistadas têm de 17 a 24 anos de idade e desenvolvem sua formação, como já mencionado anteriormente, em escola pública estadual que oferece o EM modalidade normal. Nesta parte do texto, consideraremos três dimensões para análise: a influência da família e vizinhança na escolha da escola; os sentidos atribuídos ao trabalho e a formação pedagógica na escola. 
Em entrevistas recolhidas no período investigado constatamos que a escolha pela escola teve como fator determinante as ponderações feitas pelas mães que defenderam a continuidade dos estudos, a terminalidade do EM e a possibilidade de serem introduzidas num ambiente de trabalho com maiores vantagens que nas atividades que as jovens desenvolvem atualmente. Nas entrevistas, constatamos que $21 \%$ das jovens acreditam que será possível conciliar a vida doméstica, a criação de filhos no futuro e a carreira docente. Os exemplos mais comuns dessa perspectiva de vida são da vizinhança ou dos depoimentos das professoras durante as aulas.

Para essas jovens a vizinhança teve um papel importante na escolha da escola por já terem tido suas filhas estudado nessa instituição. A escola está localizada no centro da cidade, onde ônibus, trem, metrô facilitam o deslocamento. A segurança é outro ponto importante mencionado. Não existe registro de violência na instituição, e as professoras trabalham há bastante tempo na escola. Quanto aos gestores, apontam que eles se comunicam com os alunos e famílias de forma eficiente, pois são recebidos e ouvidos. Também foi registrado que há poucas faltas de professores e se prioriza o estudo e disciplina na escola.

Todos esses fatores motivam as famílias e evidenciam o envolvimento da comunidade escolar na instituição. As famílias participam das festividades, formaturas e existe representação de mães nos conselhos escolares. Com base nesses dados, percebemos a atuação e influência das mães e vizinhança no acompanhamento da escolaridade das alunas. Segundo Ribeiro e Koslinki (2010), adolescentes que residem em vizinhanças em que a maior parte das pessoas termina o EM e alcança o ensino superior se sentirão compelidos a fazer o mesmo (p.126).

Outro dado importante diz respeito ao sentido atribuído ao trabalho e a formação pelas jovens, pelas famílias e escola. Os relatos abaixo mostram esse reconhecimento:

(...) gosto de comprar roupas, sapatos, maquiagem e só consigo isso trabalhando. Estar estudando é porque quero melhorar de vida, ter casa própria, pode viajar? (Aluna $3^{a}$ série A/2011).

Todos na minha casa trabalham. Minha mãe trabalha na zona sul do Rio há muito tempo numa casa de família. Eu trabalhei por lá um tempo ajudando a tomar conta das crianças, mas hoje eu estou numa loja vendendo roupas femininas. É puxado porque tenho que trabalhar aos sábados, então o estudo e o trabalho no futuro como professora poderá garantir eu ter folgas no sábado e domingo (Aluna $3^{a}$ serie C/2010).

Minha mãe e meu pai estudaram pouco e por isso repetem muito a importância de eu estar estudando. A escola me cansa um pouco, mas eu posso ter mais liberdade, viajar, comprar o que quero com o trabalho (Aluna $3^{a}$ serie B/2011).

Eu não sei se quero ser professora, mas quem sabe consigo depois ir para uma faculdade e vou melhorando e ter um trabalho mais remunerado? (Aluna $3^{a}$ série A/ 2010).

Não desejo seguir a carreira de magistério. Vim para essa escola por insistência dos meus pais, mas quero fazer enfermagem. Na minha classe poucas colegas pensam em ser professoras. Vão fazer vestibular para direito, administração de empresas, psicologia (Aluna $3^{a}$ serie B/2011).

Para concluir o ensino médio é mais fácil aqui porque as disciplinas matemática, química, física e outras não fazem parte do currículo do magistério. Essas disciplinas eu e minhas colegas temos mais dificuldades e nossas famílias acham importante fazermos o ensino médio. Eu quero arrumar um lugar melhor para trabalhar e fazer faculdade de turismo (Aluna $3^{a}$ serie B/2011).

Cheguei no colégio com duas amigas e já formamos um grupo que se mantem até hoje. O trabalho em grupo facilita para quem trabalha e estuda (Aluna da $3^{a}$ serie C/2012).

De acordo com Spósito (2003), haveria nos dias atuais uma maior atração dos símbolos juvenis - marcas, roupas, músicas etc, o que corresponde ao primeiro "depoimento da aluna da $3^{\mathrm{a}}$ serie A". Também está presente a representação de crescimento pessoal, de melhoria de vida e de acesso aos bens de consumo por meio do trabalho, nos demais registros. Ao mesmo tempo haveria uma certa decepção em relação ao universo escolar. Nos estudos de Madeira (1986) são citados a importância do trabalho entre as camadas populares como um valor cultural e das famílias como transmissoras de uma ideologia do 
trabalho, sendo este um provedor de status na hierarquia familiar. $\mathrm{O}$ trabalho estaria no centro dos projetos de vida e das estratégias de socialização e reprodução das camadas mais pobres.

Reconhecemos que o trabalho é importante, e não apenas sob a perspectiva da sobrevivência mas também por possibilitar outras vivências da condição juvenil, tais como acesso ao lazer, ao consumo e a realização pessoal em muitas outras áreas. Assim, é necessário haver pleno reconhecimento de que o trabalho é um direito dos (as) jovens e um componente essencial à sua formação como indivíduo e cidadão. Mas as contradições e dilemas dessa oportunidade educacional no EM precisam ser investigadas, visando a ampliar a reflexão sobre as relações entre juventude, trabalho e educação e, sobretudo, sobre os princípios e fundamentos da formação (FREITAS, 2007, p.150-152).

$\mathrm{Na}$ última década, constatamos a importância da escola média em propiciar opções para os estudantes, abrindo-se para a diversidade, construindo uma escola que incorpore a cultura própria da juventude que a compõe, quer pelas possibilidades de "formação ética e profissional, quer por ser idealizada como lócus especializado de transmissão de conhecimentos, vale ouvir e conhecer os jovens e saber o que pensam dela" (ABRAMOVAY; CASTRO, 2003).

A escola pesquisada atende a 730 jovens do ensino médio, sendo no turno da manhã 6 turmas de $1^{\text {a }}$ série e 6 turmas de $2^{\text {a }}$ serie e, no turno da tarde, 6 turmas de $3^{\text {a }}$ serie e 6 turmas de $4^{a}$ serie. Cada classe de $3^{a}$ série têm em media 30 alunos, e em entrevistas feitas com os professores e os coordenadores da instituição foi declarado que boa parte das alunas são encaminhadas para a escola pelas mães, por acreditarem que a frequência ao ensino médio relacionada a uma formação profissional representa uma possibilidade concreta de inserir-se no mercado de trabalho. O quadro de funcionários trabalhando entre 2010 e 2012 constava de 99 professores, 3 funcionários de apoio, 13 funcionários terceirizados para a limpeza, 1 diretora geral, 2 diretoras adjuntas e 2 coordenadores pedagógicos.

Quanto ao desenvolvimento de uma profissionalização, entrevistamos 52 alunas. destas, $26 \%$ revelam insegurança e desconhecimento sobre os cursos oferecidos no ensino superior e dizem "não gostar e não querer ser professor". Enquanto que, para $32 \%$ dos jovens na $3^{\mathrm{a}}$ serie, estudar no colégio pode ser uma garantia para o ensino superior; $16 \%$ revelam que pensam em investir no trabalho docente; $12 \%$ querem investir num emprego melhor; $14 \%$ estão no mercado de trabalho e esperam melhorias com a conclusão do EM. Nos depoimentos aparece de forma constante a crença de que poderão entrar numa universidade e conseguir desenvolver uma profissão. Outros revelam baixa autoestima e não acreditam que o diploma do EM poderá contribuir para o ingresso numa universidade ou profissão. Os depoimentos abaixo ilustram esse contexto.

Eu vejo que toda minha formação na escola pública não foi boa. Faltavam professores e eu gostava mesmo era de ficar conversando com meus amigos. Aqui também tem professores que procuram estimular, mas ainda sinto que não estou pronta para um concurso, um vestibular. Não me sinto capaz (Aluna $3^{a}$ série A/2012).

Trabalho numa loja no meu bairro $e$ minha mãe quer que eu consiga um trabalho melhor e ate consiga ir para uma faculdade. Sempre estudei na escola publica e o ensino é muito fraco, os professores faltam muito e essa escola tem uma preocupação com as notas, o estudo. Eu não me interesso por ser professora porque é um trabalho muito desvalorizado e cansativo, mas posso depois tentar fazer turismo, administração, sei lá... menos ser professora (Aluna da $3^{a}$ serie A/2010).

Eu estudo um pouco e quero ser professora da educação infantil. Gosto de crianças e no estagio me saio bem nas atividades e brincadeiras com as crianças (Aluna da $3^{a}$ serie C/2011).

Os depoimentos sintetizam que, no geral, existe uma perspectiva dessas jovens em finalizar o EM, conseguir ingressar no universo do trabalho e dar continuidade aos estudos na universidade. Também revela reconhecimento da precariedade da escolaridade na sua trajetória escolar. Essas expectativas vão ao encontro das pesquisas e estudos realizados por Leão et al. (2011), ao analisar os depoimentos de jovens pesquisados no Estado do Pará que parecem indicar

[...] que a constituição da condição
juvenil vem ocorrendo de forma mais
complexa, com o jovem vivendo
experiências variadas e, às vezes,
contraditórias, expostos que estão a
universos sociais diferenciados, a laços
fragmentados, a espaços de socialização 
múltiplos, heterogêneos e concorrentes. Constitui-se como um ator plural, produto de experiências de socialização em contextos sociais múltiplos, expressando os mais diferentes modos de ser jovem (p.1079).

Seja como for, cabe a pergunta: Como a escola responde a formação e expectativas desses jovens? Em que medida a organização curricular está comprometida com o ensino crítico?

O que foi possível perceber na pesquisa realizada nessa Instituição é que parece ter-se constituído um consenso entre os gestores e professores quanto à ênfase excessiva as notas dos alunos e o lugar alcançado pela escola nas provas nacionais. Os murais em locais diversos da instituição mostram os resultados alcançados e os incentivos à melhoria nas avaliações internas e externas. As propostas da gestão são sempre de recomendações quanto ao estudo, elaboração dos exercícios. e isso acaba acirrando a competição entre as classes.

Os alunos são incentivados pelos professores e coordenadores a elaborar murais dentro e fora da sala de aula para exposição dos trabalhos nas disciplinas e as medias alcançadas nos exames. Essa confecção de murais ocorre durante o período de aulas, o que causa dispersão, pois os alunos conversam enquanto os professores estão ministrando as aulas ou dedicam um número grande de horas ao trabalho extra classe na montagem dos murais, não participando das atividades desenvolvidas tanto nas salas de aula, quanto do estudo e atividades extraclasse.

De outro lado, o incentivo ao estudo e à manutenção das médias foram consideradas como um reforço na reprodução dos conteúdos e na manutenção do status da escola, por ser reconhecida, principalmente pelos pais, como uma "escola forte quanto ao ensino e a tradição", preservando o controle e a disciplina entre os alunos.

Nos murais da escola estão grandes painéis e são exibidas faixas na entrada, mostrando o resultado de vestibulares anteriores e o número de alunos que ingressaram em universidades públicas da cidade do Rio de Janeiro. Nos relatórios dos pesquisadores foram registrados o excessivo valor aos prêmios recebidos pela Secretaria Estadual, exibindo e reafirmado uma qualidade que é estimulada pela gestão publica. A qualidade vai se legitimando pelo horizonte restrito da competitividade, cuja medida é a colocação no ranking das avaliações externas.
A avaliação da qualidade por indicadores de desempenho constitui-se em uma das estratégias gerenciais de controle dos resultados e obriga estados e municípios a estabelecerem contratos de gestão, pelos quais será analisada a sua performance em relação aos objetivos pretendidos no campo educacional (Castro, 2009,p.32).

Com base em Castro (2009), é possível constatar a lógica gerencialista adotada pela Instituição, cuja perspectiva empresarial aponta resultados para a educação, onde há o deslocamento do foco da qualidade educacional para o foco da eficácia do processo, ou seja, obter o máximo de resultado com o mínimo de custo. A exposição dos resultados, assim como as atividades comemorativas para realçar as metas alcançadas tem a ver com estratégias de gestão, na qual os gestores divulgam os serviços do colégio. Também de acordo com Castro (2009) essa responsabilização dos gestores mostram os resultados da logica gerencial de prestar contas sobre os serviços prestados.

Esse modelo de gerenciamento está em consonância com o modelo Estado- empresário, que tem como meta promover condições adequadas para a eficiência pública, sendo possível perceber que há um modelo de competências,

Foi possível perceber que há um modelo de competências, que insere dentro do processo de aprendizagem "alguns conhecimentos e habilidades que propiciem a formação de alunas adaptadas às "imprevisões e pretensos desafios do processo produtivo" que, de acordo com Gabriel (2008), reforçam dimensões cognitivo comportamentais, capazes de adequar as subjetividades às características, tais como a implicação, iniciativa, a concorrência.

Para fazer circular esse conhecimento que está previsto no currículo, a escola organiza-se em dois turnos, e cada um deles têm um coordenador responsável pelas orientações pedagógicas e administrativas aos alunos, professores e funcionários. Nas pesquisas, foram registradas a falta de comunicação entre os coordenadores dos diferentes turnos, o que dificulta a coesão das ações. Nesse cenário, a busca da "qualidade educacional" pode ser identificada com a permanência do aluno na escola e, as medidas tomadas quanto ao processo de ensino aprendizagem apontam para a preocupação com a melhoria da eficiência e eficácia do sistema de ensino (COSTA, 2009, p.47). 
Há um grande investimento da escola nas atividades esportivas, e os professores incentivam a participação das alunas, apesar de os materiais nem sempre estarem disponíveis no momento das aulas, o que acarreta atrasos para o seu início. Uma quadra poliesportiva aberta é utilizada para as aulas, e outra quadra fechada, chamada de "Multimeios", é onde se realizam as festas, apresentações dos discentes planejadas pelos professores de artes como teatros, recitais ou de outros projetos desenvolvidos durante o ano de forma interdisciplinar ou não. Algumas peças teatrais são ensaiadas pelos alunos sem a mediação dos professores, e esses alunos elaboram as coreografias e divulgam as apresentações nos murais.

Observa-se, assim, que em geral as práticas pedagógicas desenvolvidas na escola de ensino médio se apresentam eivadas por um certo pragmatismo, o que implica repensar a lógica de organização e participação na escola, pois evidencia-se a ampliação de "eventos" esporádicos em detrimento de projetos com práticas educacionais mais críticas.

\section{Cultura escolar e organização curricular: pendências políticas e pedagógicas}

Reformas educacionais e especialmente as relativas à formação de professores vêm sofrendo profundas transformações desde a década de 1990, impulsionadas pelas recomendações dos organismos internacionais aos países periféricos, estabelecendo uma reestruturação em consonância com o processo de um "novo capitalismo", que, por sua vez, institui a necessidade de um novo perfil de trabalhador, a partir do qual se generaliza o movimento de implantação de um novo modelo de formação.

A concepção de educação é a de um "novo homem", cujo mote de sua formação será a de ser capaz de: flexibilidade, empregabilidade, multifuncionalidade e polivalência, bases para a capacidade de adaptação do indivíduo à nova morfologia do trabalho" (ANTUNES, 2005, p.13), da abertura das economias, da mundialização do capital. Nesse sentido, a educação profissional promove a individualização da formação do trabalhador, pelo qual se indica que cada um é responsável na busca de competências a serem alcançadas com o desenvolvimento de habilidades básicas e específicas, na procura de inserção no mercado de trabalho.

Nesse sentido, as mudanças educacionais têm sido as palavras de ordem para o mundo vivido, e um dos exemplos disso pode ser constatado com o previsto na Lei n. 11.274/2006, que é motivo de preocupação e perplexidade, em face do despreparo do professor para atender às exigências da reestruturação do ensino fundamental para nove anos e das mudanças na educação infantil instituídas formalmente em 2006 (BRZEZINSKI, 2008p. 180). Cabe alargar a abordagem, considerando os problemas concretos vivenciados pelas jovens que frequentam o ensino médio e as reais possibilidades de inserção profissional que estes podem vislumbrar.

Ainda que a Lei 11.274/2006 retrate a intenção do MEC/SEB/DPE/COEF de construir políticas indutoras de transformações significativas na estrutura da escola, na reorganização dos tempos e dos espaços escolares, nas formas de ensinar, de aprender, de avaliar, implicando a disseminação das novas concepções de currículo, conhecimento, desenvolvimento humano e aprendizado (BRASIL, 2006), é preciso termos presente que a democratização do ensino não se dá somente pela garantia do acesso, pois a desigualdade e a exclusão ainda permanecem, principalmente a exclusão gerada pelo não aprendizado ou pelo aprendizado insuficiente.

Portanto a busca pela qualidade da educação requer medidas para além do campo do ingresso e da permanência, e ações capazes de reverter a situação de baixa qualidade da aprendizagem na educação básica.

Quando a Lei 11.274/2006 é promulgada, instituindo o Ensino Fundamental com nove anos de duração para atender crianças a partir dos seis anos de idade, fica estabelecida uma política pública afirmativa de equidade social implementada pelo Governo Federal, com intenção de: "oferecer maiores oportunidades de aprendizagem no período da escolarização obrigatória e assegurar que, ingressando mais cedo no sistema de ensino, as crianças prossigam nos estudos, alcançando maior nível de escolaridade". Essa política, que altera o Ensino Fundamental de oito para nove anos, acirrou os debates sobre o desenvolvimento dos currículos e a defesa de se privilegiar as vivências das crianças e sua cultura, criando condições para a potencialização de valores democráticos.

Brzezinski (2008) aponta que há uma crise na função da escola, uma vez que, ao longo do século $\mathrm{XX}$, estiveram presentes duas funções: promover a apropriação do conhecimento considerado socialmente relevante e formar para a cidadania. Para a autora, as duas estão em crise, seja pela dificuldade em realizá-las, seja pelo anacronismo em relação aos tempos presentes.

Dessa forma, coloca-se em questão o direito à educação e o posicionamento do Estado frente à função da escola e a materialização de 
políticas educacionais que garantam às jovens alunas das camadas populares a ampliação, com qualidade, da escolarização básica. Muitas indagações emergem no que tange às jovens que frequentam o Ensino Médio, modalidade Normal, tais como: Quais seriam os interesses do Estado em manter as jovens na escola? A quem interessam as discussões sobre a escolarização juvenil no Brasil? Não seria, até hoje, uma das funções da escola ocupar o tempo livre dessas jovens, para que não gerem problemas sociais, como está presente no imaginário de muitos?

Para Mogarro (2005), a cultura escolar apresenta uma natureza profunda e naturalmente histórica. É constituída por um conjunto de teorias, ideais e princípios, normas, regras, rituais, rotinas, hábitos e práticas que nos remetem às formas de fazer e pensar os comportamentos sedimentados ao longo do tempo e que se apresentam como tradições, regularidades e regras partilhadas pelos atores educativos no seio das instituições. (p. 105)

A produção dessa cultura e sua compreensão exigem não só um trabalho de elaboração e procura de fontes como também segundo Felgueiras (2005) o recolhimento junto às pessoas das simbolizações construídas, que assumem processos dinâmicos de conflito e mudança.

Refletir e propor uma cultura escolar mais qualitativa exigirá adequação: na proposta pedagógica, no material didático, na formação do professor, bem como nas concepções de espaçotempo escolar, currículo, avaliação, infância, aluno, professor, metodologias. Santos (2007), contribui para o esclarecimento quanto ao papel da cultura e do cotidiano frente aos compromissos que a escola deve assumir. Assim, reflete a autora "falar de currículo escolar coloca-nos diante de um grande desafio. Como abordar essa temática sem parecer um burocrata do sistema, disposto a criar mais normas e regras, sem prestar atenção em como elas funcionam ou não [...]" (p. 296).

Para a autora a participação dos estudos culturais na alteração das políticas e das práticas curriculares têm crescido no Brasil, pois questiona-se a natureza dos currículos tradicionais e cognitivistas, alertando para uma postura acrítica que ocasiona o empobrecimento curricular.

Para Dias e Lopes (2003), “a recontextualização do currículo da formação de professores baseada nas competências modifica $o$ foco da aprendizagem escolar, na qual os conteúdos e as disciplinas passam a ter valor apenas como meios para a constituição de competências".
Essa formação baseada em competências traz consequências no/para o exercício do trabalho docente, na medida em que são favorecidas e reguladas as ações dos professores, através de modelos de ensino e de avaliação a serem seguidos. O centro do ensino deixa de ser o saber do professor, que constitui a base para o desenvolvimento de seu trabalho no processo de ensino-aprendizagem, restringindo-se ao domínio de competências. A esse respeito, Ramos (2001) assinala que

A ideia que se difunde quanto à
pertinência do uso da noção de
competência pela escola é que tal noção
seria capaz de promover o encontro entre
trabalho e formação. No plano do
trabalho, verifica-se o deslocamento do
conceito de qualificação em direção à
noção de competência. No plano
pedagógico, testemunha-se a organização
e a legitimação da passagem de um
ensino centrado em saberes disciplinares
a um ensino definido pela produção de
competências verificáveis em situações
concretas e específicas. Essas
competências são definidas em relação
aos processos de trabalho que os sujeitos
deverão ser capazes de compreender e
dominar.

A organização pedagógica, as instituições de ensino e formação têm-se organizado com base em uma estrutura nuclear - classe, entendida como um grupo de alunos que recebe em conjunto e de forma simultânea o mesmo ensino. Trata-se de um modo de organização que se consubstancia no princípio de ensinar a muitos como se fosso a um só (BARROSO, 2003). Essa solução organizacional foi sendo naturalizada, e essas contradições e dilemas marcam os antigos e novos arranjos sociais e educacionais, que necessitam ser observados e analisados para a contribuição não somente do debate político, mas também para dirigir algumas interrogações e reflexões, para pensar os jovens e sua inserção no mundo do trabalho docente. Sob a perspectiva do movimento que defende a formação em nível superior do professor nas séries iniciais do ensino, trata-se de um retrocesso.

Observa-se que a organização curricular, para o ensino médio modalidade normal, compreende uma base comum e outra diversificada, na qual a primeira busca a formação geral, construindo competências e habilidades básicas para a continuidade dos estudos e preparação para o trabalho. A parte diversificada 
está orientada para o atendimento as metodologias do ensino, estágios e práticas didáticas bem como procura atender as características regionais e locais, permeando a cultura, a economia e a política onde esta se insere, conforme recomendações dos PCNs para o ensino médio. Quanto ao Projeto Político Pedagógico, é de responsabilidade da escola a construção.

De acordo com a pesquisa feita com os gestores da instituição, o trabalho educativo tem como objetivos desenvolver estratégias político pedagógicas para a organização do ensino, garantir a qualidade educativa e promover praticas de gestão que visem estruturar a capacidade de decisão quanto aos serviços essenciais da educação. Esses propósitos estão registrados no Projeto Politico Pedagógico construído em 2005 por parte dos professores e coordenadores e tem sido avaliado e ampliado no inicio de cada ano segundo depoimento da diretora. Esse PPP em construção não permitiu uma consulta.

Com base nessas análises, interessa-nos aprofundar as aspirações da juventude que escolhe esse curso profissionalizante para apreendermos o sentido dessa profissionalização e as políticas que assinalam uma lógica que ambiciona promover mudanças sociais através da educação, vinculando expansão do ensino a discursos de valorização na formação inicial docente. Para isso, faz-se necessário recorrer aos elementos que determinam as políticas de formação, entre estas as condições históricas de sua produção, as correlações de força em presença e as perspectivas teóricas partilhadas.

Consultando a Resolução SEEDUC $\mathrm{n}$. 4.376 (18/12/2009), verifica-se que no corpo do texto é mencionada a apreciação e aprovação da adequação da Matriz Curricular do Curso para as escolas de ensino médio da Rede Pública Estadual de Ensino. Informa, ainda, que a Matriz Curricular apresentada é o resultado do trabalho do Centro de Estudos instituído em 2008 nas unidades escolares, e que, durante a realização de encontros na Secretaria de Educação, foram debatidos temas voltados para a formação profissional do professor, as tendências neste campo, a organização do currículo, a base nacional comum, a parte diversificada, a prática como espaço formativo.

Acreditamos ser pertinente trazer o trabalho educativo dessa instituição de Ensino Médio modalidade Normal, no momento em que se debate a formação e se questionam os saberes dessa prática pedagógica. A implementação da escola está amparada em um conjunto de providências legais para a ampliação da proposta para o Ensino Médio Normal, de acordo com o Parecer n. 122, de 10 de novembro de 2009, a Resolução SEEDUC (Secretaria de Educação do Estado do Rio de Janeiro) $\mathrm{n}^{\circ} 4.376$, de 18 de dezembro de 2009, e a Portaria SEEDUC n. 91, de 29 de março de 2010.

Extinto o curso normal, em atendimento à LDBEN n. 9.394 de 1996, tentativas pela reafirmação de seu reconhecimento e permanência foram assumidas, colocando em discussão as contribuições da escola de ensino médio na formação de parcela significativa de jovens. O Rio de Janeiro é único estado da região sudeste que oferece o curso de formação em Magistério Escola Normal, em Escolas de Ensino Médio.

Assim, ao focalizarmos a expansão, no Rio de Janeiro, de cursos em nível médio normal, para a formação de professores para a educação infantil e para as primeiras séries do ensino fundamental, pretendemos discutir a consolidação da formação nesse nível de ensino como política pública, não transitória. Nesse contexto, buscamos explicitar os sentidos do acesso e permanência nos cursos e a incorporação desses jovens alunos na luta permanente pelas novas oportunidades à educação.

Visamos, também, analisar a ação do Estado nas políticas de formação que vêm se caracterizando, de acordo com Freitas (2007), pela fragmentação, consequentemente assegurando diferenciadas dimensões de profissionalização. Isso pode ser evidenciado quanto ao oferecimento do ensino médio normal, já que a pressão da juventude pela profissionalização após o ensino fundamental coloca imenso contingente de jovens no exercício do magistério e na expectativa de se profissionalizarem. Essas iniciativas ocultam a oferta diferenciada de cursos e programas, apontando para a desigualdade da formação oferecida nas instituições de ensino e nas instituições de pesquisa, na formação de jovens alunos que estudam e pesquisam e daqueles que trabalham, produzindo condições diferentes de exercício profissional e desigualdade educacional (p.146).

São necessários mais de 230 mil professores no ensino médio e cerca de 500 mil no ensino fundamental, para atender ao número de estudantes hoje existentes na rede pública. Brzezinski (2008) ressalta que ações pontuais de formação de professores pouco resolverão a falta de docentes qualificados para a educação básica, principalmente para o desenvolvimento educacional nas séries iniciais do ensino. Simultaneamente, a história comprovará o alcance de indicadores de qualidade, já que os resultados qualitativos divulgados nos dados oficiais sobre a escola pública, infelizmente, apontam para a desqualificação no ensino fundamental e, mais 
ainda, a falência do ensino médio. (BRZEZINSKI, 2008, p.169).

\section{Considerações Finais}

Diante desse breve panorama acerca da situação de pessoas jovens frente ao mundo do trabalho, é inegável que este se configura como de suma importância para os segmentos juvenis. Coloca-se em debate o fato de que a manutenção do nível médio normal reafirma-se como política, desconsiderando o Plano Nacional de Educação, que estabelece metas para a formação superior dos professores da educação básica.

Para Freitas (2007), com o oferecimento desse curso evidencia-se o divórcio entre as necessidades atuais da educação infantil e ensino fundamental com a proposta de formação da juventude no ensino médio para a docência. Daí a relevância de discutir o trabalho que vem sendo realizado para fazer frente ao trabalho concreto para as séries iniciais do ensino.

Considerando os registros feitos pelas jovens alunas, podemos questionar os elementos que apontam substantivamente para o significado do trabalho e da formação. As representações acerca do trabalho para essas jovens direcionamse para a necessidade, fonte de independência, crescimento e auto realização. Quanto à formação, existe o forte ideal de continuar os estudos numa universidade. Consultando as professoras e os registros da escola dos egressos, as alunas ingressam ao sair da escola de ensino médio normal em instituições públicas e privadas de ensino superior e a maioria acaba fazendo a opção pelo ensino privado e conseguem bolsas de estudo para esse fim. Seja como for, ao examinarmos os depoimentos das jovens alunas, destacados ao longo do texto, identificamos:

a) A escola precisa, de acordo com Moreira (2010), "ampliar-se, abrir-se, aumentar as oportunidades de acesso às ciências, às artes, a novos e diferentes saberes, a novas linguagens, a novas interações, a outras lógicas, à capacidade de buscar conhecimentos, ao aprofundamento, à sistematização e ao rigor" (p.110);

b) A vida escolar representa para as famílias como um lugar de crescimento pessoal e profissional, podendo ter maiores chances de ocupação no mercado de trabalho, diferente da condição paterna que, de acordo com os depoimentos, tiveram a escolaridade inconclusa;

c) $\mathrm{O}$ entendimento de que o trabalho relaciona-se a uma "fonte de independência", pois este significado é praticamente universal e transparece em todo o tipo de jovem, de acordo com as análises de Branco (2008), que reflete acerca da atração que o trabalho exerce sobre o jovem.

d) $\mathrm{O}$ trabalho expressa-se pela metáfora "crescimento" e "auto-realização", que envolvem as "transformações no aparato produtivo e seus elos com a dinâmica do mercado de trabalho" (GUIMARAES, 2008, p.169). São fatores que explicam oportunidades preenchidas e percursos desenvolvidos nos diversos ambientes de trabalho.

e) O curso de formação docente no EM é concebido com base nas "facilidades curriculares", seja pelas disciplinas consideradas como de exigências menores para a conclusão da escolaridade de nível médio, seja pelas metodologias de trabalho pedagógico que privilegiam atividades em grupo.

f) "As práticas partem do pressuposto de que as alunas necessitam de um currículo que as leve a algo mais que a simples memorização (...) assim, as contribuições dos estudos culturais e das aplicações do conceito de cultura no desenvolvimento curricular vem sendo positiva e indicam uma reivindicação antiga de segmentos e setores da sociedade" (Santos, 2007, p. 301);

g) Pelas falas, podemos depreender que essas experiências em grupo não têm sido sólidas e reforçam a fragmentação, na medida em que há o entendimento de cada um possa cumprir tão somente a "tarefa" solicitada pelo professor a cada componente do grupo, ou seja, a distribuição de diferentes funções entre os componentes de cada grupo, permite que uma das alunas digite o trabalho, a outra faça a apresentação, uma terceira realize a pesquisa e assim por diante. Essas atitudes revelam pouco investimento na autonomia intelectual e aprendizado coletivo.

Retomando a questão da execução de "tarefas", cabe lembrar a discussão empreendida por Kuenzer (1999), ao discutir que no processo de formação docente tem sido privilegiado o treinamento do professor, como se fosse esperado o simples cumprimento de atividades já "dadas" em modelos. Assim, ao professor "compete realizar um conjunto de procedimentos 
preestabelecidos" (p. 182), retirando de seu trabalho a dimensão de cientista e pesquisador de educação, e transformando-o em um profissional que a autora denomina como "professor tarefeiro". Em outras palavras, é necessário que a escola vislumbre constituir-se em possibilidade de autonomia, de expansão dos horizontes, de novas perspectivas, de novas condutas e conhecimentos (MOREIRA; CANDAU, 2008).

Para De Rossi (2005), pensar sobre o cotidiano das escolas, pela via da organização da cultura escolar, significa reconhecer como o Estado utiliza a escola como recurso de convencimento e de emotividade bastante mobilizadores para banir individualidades e para fazer a conversão pela subjetividade, sem alterar as condições materiais dos sujeitos envolvidos. Dessa forma, a pesquisa realizada na instituição revela a priorização do produto em detrimento do processo.

\section{Referências Bibliográficas}

ABRAMOVAY, M., CASTRO, M. G. Juventude, juventudes: o que une e o que separa. Brasília: UNESCO, 2003.

ANTUNES, Ricardo. O caracol e sua concha: ensaios sobre a nova morfologia do trabalho. São Paulo: Boitempo, 2005.

BARROSO, J. Organização e Regulação dos ensinos básico e secundário em Portugal: sentidos de uma evolução. Educ. e Soc. Campinas, v. 24, n. 82, p. 63-92, 2003.

BRASIL/PR. Lei n.11.274, de 6 de fevereiro de 2006. Altera a redação dos arts. $29,30,32$, e 87 da Lei n. 9.394, de 20 de dezembro de 1996.

BRASIL. Resolução CNE/CBE n.1, de 20 de agosto de 2003. Dispõe sobre os direitos dos profissionais da educação com formação de nível médio, na modalidade Normal, em relação à prerrogativa do exercício da docência, em vista do disposto na Lei n.9394/96, e dá outras providências. Diário Oficial da União. Brasília, 22 ago.2003, seção 1, p.12.

BRASIL/PR. Lei n. 11.502, de 11 de julho de 2007. Modifica as competências e a estrutura organizacional da fundação Coordenação de Aperfeiçoamento de Pessoal de Nível Superior. Disponível em: <http://www.planalto.gov.br/CCIVIL/Ato2007/20
10/2007/Lei/L11502.htm>. Acesso em: 31 out. 2010.

BRASIL, RESOLUÇÃO SEEDUC n. 4.376, de18 dez. 2009.

BRASIL, PORTARIA SEEDUC n. 91 de 29 mar. 2010.

BRANCO, P. Juventude e trabalho: desafios e perspectivas para as políticas públicas. São Paulo: Editora Fundação Perseu Abramo, 2008.

BRZEZINSKI, I. LDB dez anos depois. São Paulo: Editora Cortez, 2008.

CASTRO, J. Evolução e desigualdade na educação brasileira. In: Educ. Soc., Campinas, v. 30, n. 108, p. 673-697, out. 2009.

COSTA, J. Perspectivas da juventude na sociedade de mercado. In: NOVAES, R; VANNUCHI, P. (orgs). Juventude e Sociedade. Trabalho, educação, cultura e participação. São Paulo: Editora Fundação Perseu Abramo, 2009.

DE ROSSI, V. L. S. Projetos pedagógicos no jogo da ilusão versus esquecimento. In: CORBALAN, A.. (Coord.). Enredados por lá educación, la cultura y la política. Buenos Aires: Biblos, 2005.

DIAS, Rosanne Evangelista, LOPES, Alice Casimiro. Competências na formação de professores no Brasil: o que (não) há de novo. Educ.Soc., dez. 2003, vol.24, nº .85 , p.1155-1177. ISSN 0101-7330.

FELGUEIRAS, Margarida. Materialidade da cultura escolar. A importância da museologia na conservação/comunicação da herança educativa. Pro-Posições. Campinas, São Paulo, v.16, n. I (46), jan/abr, 2005.

FREITAS, H. Certificação docente e formação do educador: regulação e desprofissionalização. Educ. Soc., Campinas, v.24, n. 85, p.1095-1124, dez. 2003.

Dez anos de LDB: tensões e contradições na formação dos profissionais da educação. In: SOUZA, V. Formação de professores para a educação básica: dez anos da LDB. Belo Horizonte: Autêntica, 2007.

GABRIEL, C. T. Conhecimento escolar, cultura e poder: desafios para o campo do currículo em tempos "nós". In: MOREIRA, A. F.\& CANDAU, 
V. M(orgs). Multiculturalismo: diferenças e práticas pedagógicas. Petrópolis: Vozes, 2008.

GATTI, B.; BARRETO, E. S de S. Professores do Brasil: impasses e desafios: Brasília, Unesco, 2009.

GUIMARÃES, N. Trabalho: uma categoria-chave no imaginário juvenil? In: ABRAMO, $\mathrm{H}$, BRANCO, P. Retratos da juventude brasileira. São Paulo: Ed. Perseu Abramo, 2008.

KUENZER, Acacia Z. As políticas de formação: a constituição da identidade do professor sobrante. Educ. Soc., ano XX, nº 68, p. 163-183, dez. 1999.

LEÃO, G.; DAYRELL, J.; REIS, J. Juventude, projetos de vida e ensino médio. Educ. Soc., Campinas, v.32, n.117, p. 1067-1084, out.-dez. 2011.

MADEIRA, F. R. Os jovens e as mudanças estruturais na década de 70: questionando pressupostos e sugerindo pistas. Cadernos de Pesquisa, São Paulo, n. 58, v. 80, ago. 1986.

MOGARRO, Maria João. Os arquivos escolares nas instituições educativas portuguesas. Preservar a informação, construir a memória. Pro-Posições. Campinas, São Paulo, v.16, n. I (46), jan/abr 2005.

MORAES, C.; ALAVARSE, O. Ensino Médio: possibilidades de Avaliação. Educ. e Soc., Campinas, v. 32, n. 116, p. 807-838, set. 2011.
MOSCOVICI, S. Representações sociais: investigações em psicologia social. Petrópolis, RJ: Vozes, 2009.

MOREIRA, A. F. B. Políticas de Currículo: repercussões na prática. XV ENCONTRO NACIONAL DE DIDÁTICA E PRÁTICA DE ENSINO (ENDIPE): Convergências e tensões no campo da formação do trabalho docente, 2010, Belo Horizonte. Anais eletrônicos... Belo Horizonte: UFMG, 2010, CD.

MOREIRA, A. F. B e CANDAU, V. M. Currículo, conhecimento e cultura. In: BRASIL. MEC, SEB. Indagações sobre Currículo. Brasília, 2008.

RAMOS, Marise N. A pedagogia das competências e a psicologização das questões sociais. Boletim Técnico do Senac, Rio de Janeiro, v. 27, n. 3, p. 01-64, 2001

RIBEIRO, L. C.; KOLINSKI, M (orgs). Desigualdades urbanas, desigualdades escolares. Rio de Janeiro: Letra Capital: observatório das metrópoles. IPPUR/UFRJ, 2010.

SANTOS, L. Currículo em tempos difíceis. Educ. Rev., Belo Horizonte, n. 45, jun. 2007, p.291-306.

SPÓSITO, M. P. Uma perspectiva não escolar no estudo sociológico da escola. Revista USP. Seção Textos, n. 57, pp. 210-226, mar.-mai./2003. 


\section{Notas}

1 Esse artigo toma por base a monografia premiada com o segundo lugar no Concurso "Prêmio Ministro Gama Filho", da Escola de Gestão e Contas do TCE/RJ, cujo tema do Edital 02/2012 versou sobre "Políticas Públicas em Educação".

2 De acordo com os dados da Pnad, 2006, que considerou jovens os sujeitos na faixa etária compreendida entre 14 e 29 anos.

\section{Sobre as autoras:}

Leny Cristina Soares Souza Azevedo: Universidade Federal do Rio de Janeiro, Rio de Janeiro.

Ligia Karam Corrêa de Magalhães: Universidade Federal do Rio de Janeiro, Rio de Janeiro. 